\title{
APRESENTAÇÃO DO NÚMERO
}

Bruno Anselmi Matangrano Enéias Tavares

\section{UM FANTÁSTICO BRASILEIRO MÚLTIPLO E NECESSÁRIO}

A literatura brasileira, desde o romantismo, é permeada de elementos do que hoje se conhece como "insólito ficcional": não raro, usados por autores e autoras para reinterpretar o popular, o histórico, o exótico, o regional ou o folclórico, registrar inquietações de seu tempo e espaço, propor reflexões ou hipóteses interpretativas à realidade - ou até mesmo criar outras realidades relacionadas, ou não, com a nossa - e também para confrontar o status quo político, cultural e social. É desse esforço que resultam contos baseados nos imaginários indígenas, europeus e africanos, novelas de temática espiritualista, narrativas de fantasmas e monstros em geral, aventuras interespaciais, ou ainda novos universos inteiramente diferentes - ou não-do mundo considerado real, além de romances, contos e crônicas de ficção científica que propõem espaço e tempo outros, ambientados num aqui e agora que nunca aconteceram ou em um futuro próximo ou distante passível de ainda se concretizar, para nosso fascínio, maravilhamento, contentamento ou pavor.

Enquanto exercício imaginativo, naquilo que chamamos de "Fantástico Brasileiro" - projeto de extensão, sediado na UFSM, que até o momento resultou numa exposição itinerante, em vários colóquios, dissertações, teses e artigos, bem como em um livro crítico-historiográfico (Arte \& Letra, 2018) -, o insólito em nosso país 
sempre foi uma constante, mesmo que a crítica e as universidades antes o ignorassem, tanto na seara das obras de autores reconhecidos, nos quais o elemento insólito foi constantemente ignorado ou apagado, quanto no concernente a autores que apenas se dedicaram a essa produção e que correram por muito tempo o risco de desaparecer completamente, por puro preconceito ou elitismo literário, como vozes inauditas ou ignorados de uma produção ficcional problemática - segundo muitos dos nossos críticos -, por questões tanto estilísticas quanto temáticas, muitas vezes mascarando juízos de valor superficiais.

Nas últimas décadas, porém, a produção fantástica aumentou de tal forma que não pôde mais ser ignorada pelos estudos literários e pela grande mídia, a ponto de ganhar a atenção tanto de grandes editores quanto da crítica universitária. Comprovam isso tanto a criação de selos dedicados à produção fantástica nacional em grandes grupos editoriais como Rocco, Cia das Letras, LeYa, Record e outros, quanto o surgimento de uma série de pequenas editoras voltadas a esse segmento, além da multiplicação de livros, artigos, dissertações e teses, resultantes de projetos de pesquisa realizados em diversas universidades do país, sobre a literatura insólita, em geral, e sobre o fantástico brasileiro, em particular. A revista Abusões e o próprio grupo de pesquisa que a produz - "Nós do Insólito: Vertentes da Ficção, da Teoria e da Crítica", certificado pela UERJ junto ao Diretório de Grupos do CNPq - refletem o vigor de ações e reflexões que constituem o atual momento dos estudos do fantástico em suas mais variadas vertentes em nosso país.

Em vista disso e pela forte defesa que fazemos do Fantasismo como um novo movimento literário contemporâneo, que marca 
as transformações pelas quais o mercado editorial vem passando nas últimas duas décadas, recebemos com alegria o convite de organizar este sétimo número da Abusões, dedicado justamente ao Fantástico Brasileiro contemporâneo, delimitado, por fins didáticos, pela produção publicada entre o início da década de 1980 e o ano corrente de 2018. O resultado da chamada e da nossa seleção de textos pode ser conferido nos treze artigos que formam o dossiê temático, ao mesmo tempo variado e coeso, em um registro da produção diversa e instigante do cenário atual e das diversas energias criativas que têm permeado a cena literária fantástica do Brasil nos últimos trinta anos.

Nos trabalhos selecionados, os leitores encontrarão discussões que apontam para diversas correntes teóricas e também ficcionais, como a história alternativa; a ênfase no folclore; a crítica política através do insólito; a alta fantasia como resistência social; a releitura dos clássicos no steampunk brasileiro; o cenário urbano contemporâneo como palco da ficção especulativa; a potencialidade dos diferentes gêneros narrativos - romances, contos e minicontos - enquanto meios para a ficção fantástica; as relações entre marginalidade, distopia e tecnologia na seara da ficção, entre outros temas que são apresentados pelos autores nesse dossiê.

Esse conjunto de artigos aponta a diversidade de estilos de escrita que enriquecem a cena contemporânea, ao mesmo tempo em que evidencia a pluralidade de formas de se analisar essa novíssima produção e destacar-lhe o valor literário e o papel no mercado e na formação do público leitor. Aponta também, de um lado, as transformações dessa literatura desde a década de 1980, a exemplo do livro A Casca da Serpente, de J. J. Veiga, analisado em 
um dos artigos, autor cuja obra pertence e mantém um diálogo com a geração de 1960 e com o realismo maravilhoso, movimento que se destacou na literatura latino-americana do século XX; de outro, valoriza as produções ultrarrecentes, como Ordem Vermelha: Filhos da Degradação, de Felipe Castilho, publicado em dezembro de 2017, por ocasião da grande convenção de fãs CCXP, em São Paulo, em uma das maiores ações já feitas para divulgação de um livro fantástico nacional, o que resultou na permanência do livro por várias semanas na lista de mais vendidos.

Depreendem-se também desses estudos algumas marcas consideradas importantes na literatura fantasista, como o diálogo com a tradição a partir de um olhar antropofágico essencialmente brasileiro e modernista, percebido em obras bastante distintas como a aventura policial A Lição de Anatomia do Temível Dr. Louison, de Enéias Tavares, concebida a partir da estética steampunk e a ficção científica experimental de Luis Brás, de Pequena Coleção de Grandes Horrores, coletânea na qual a obra Macunaíma, de Mário, de Andrade é repensada. Isso também se manifesta pela retomada de interesse por temas tradicionais de nossa cultura, como se vê na nascente "ficção folclórica" - termo teorizado e defendido em um dos artigos deste dossiê -, literatura que se diferencia de outras tentativas de obras nacionalistas, por trazer elementos da cultura popular brasileira e, mais especificamente, do nosso folclore, numa visada contemporânea que os incorpora à nossa realidade, sem tratá-los como "curiosidade", "exotismo" ou "regionalismo", como foi feito pontualmente ao longo de nossa tradição.

O interesse e a preocupação com a diversidade, bem como a consequente inclusão de grupos minoritários com protagonismo em 
narrativas fantásticas, também se apresentam como característica das vertentes mais contemporâneas do Fantástico Brasileiro - o chamado Fantasismo -, a exemplo de livros como As Águasvivas não sabem de si, de Aline Valek, Ordem Vermelha: Filhos da Degradação, de Felipe Castilho, Deixe as estrelas falarem, de Lady Sybylla, e Exorcismos, amores \& uma dose de blues, obras analisadas nos textos aqui apresentados, nas quais vemos personagens de etnias e sexualidades diversas com voz e protagonismo.

Por fim, percebe-se ainda nessa literatura fantasista em análise a busca por uma linguagem elaborada, com preocupações rítmicas e semânticas, responsável pelo bem-vindo apagamento da hierarquia e do estigma por tanto tempo presente entre literatura popular e literatura erudita, gerados pelos preconceitos em relação às vertentes do insólito ficcional produzidas no Brasil. Obras assumidamente fantásticas, como as de Luís Brás, Enéias Tavares e Eric Novello, apontam nesse sentido de uma busca por experimentações estilísticas, enquanto as de Christiano Aguiar, Joca Reiners Terron, Amilcar Bettega, Nuno Ramos e Rubem Fonseca todos eles analisados em artigos desse número -, nascidas no seio da dita "alta literatura", valem-se de elementos insólitos e brincam com as diversas possibilidades de realidade, em um apagamento dessas fronteiras que abre espaço para novas experimentações e pontos de contato entre esses dois caminhos que não por tanto tempo foram mantidos distantes; na verdade, sempre dialogaram.

Completam o número duas entrevistas e uma resenha, que também elucidam as diversas direções do fantástico nacional. Em primeiro lugar, a entrevista de Alexander Meireles da Silva evidencia os caminhos de trabalho de um professor igualmente 
engajado com a pesquisa - através de livros, artigos e orientações - e com a divulgação da ciência para o grande público através de seu canal no Youtube, o Fantasticursos, em um louvável trabalho de popularização da ciência e incentivo ao estudo de literatura e à leitura. Em segundo, a conversa com Eric Novello, escritor e tradutor de igual talento e visibilidade em nosso mercado, mostra os caminhos, não raro tortuosos, que unem a produção ficcional e o ofício tradutório. Nessa entrevista, o autor comenta as nuances de suas obras e de seu processo criativo, suas influências e fontes, bem como os desafios de se fazer uma literatura insólita de preocupações estilísticas, em um intenso diálogo com a música e com o cinemaarte. Por fim, a resenha de Poéticas do Mal, coletânea de ensaios críticos e historiográficos, organizada por Júlio França, fornece aos leitores do número um bom exemplo da produção científica atual em torno da literatura insólita, produção que faz do Brasil um país não só de escritores e leitores do fantástico como também de estudiosos do insólito. O livro organizado por França demonstra a importância e a presença do fantástico nas letras brasileiras desde sua origem, sem as quais o atual momento de efervescência da cena contemporânea seria impossível.

Não poderíamos finalizar essa Apresentação sem ressaltar que nossa felicidade com o resultado deste número composto por artigos tão interessantes, engajados e instigantes, é tristemente transpassada pelo momento turbulento e perigoso no qual nos encontramos politicamente. Na contramão dos esforços de resgate de nosso patrimônio cultural anterior e valorização da produção contemporânea, em um país "sem memória", como descrito por muitos teóricos e pesquisadores, o incêndio do Museu Nacional da 
UFRJ marca uma cicatriz indelével em nossa história e em nosso patrimônio, tanto o material quanto o simbólico. Paralelamente, escrevemos esse texto entre o primeiro e o segundo turno das eleições presenciais de 2018, marcadas pelo preconceito, pelo conflito, pela desconfiança e insegurança, tão combatidos na literatura fantasista, faz-nos pensar ainda mais na necessidade premente da arte, da literatura e da imaginação, para resistirmos ao futuro sombrio que se nos apresenta. Não por acaso, vivemos com o Fantasismo um momento de florescimento das Distopias, bem como o resgate das narrativas distópicas clássicas, que desde os anos 1960 vem nos ensinando e tentando nos alertar contra os perigos da intolerância. Essas questões perpassam alguns dos artigos aqui reunidos, servindo como testemunho do momento histórico e das preocupações que permeiam a produção literária e crítica contemporânea.

Se há uma resposta ao ódio, à a patia, à opressão e ao preconceito, esta tem de ser inicialmente produzida na paisagem mental e intelectual dos seres humanos, para só então ecoar no mundo das relações sociais. Nesse aspecto, nossa ficção insólita brasileira tem produzido respostas coerentes, perguntas e hipóteses ficcionais que urgentemente precisam ser lidas, debatidas e repensadas. Talvez aí se encontre a força necessária para (re)descobrirmos o nosso passado, valorizarmos nosso patrimônio e recuperarmos nossa memória, enquanto (re)construímos o que para muitos continua sendo o ambíguo país do futuro. 